Check for updates

Cite this: RSC Adv., 2017, 7, 31950

\title{
A simple method to control the microstructure and properties of sol-gel silica antireflective coatings $\dagger$
}

\author{
Yingying Sun, $\$^{a}$ Jiaxian Zheng, $\$^{a}$ Rongchao Huang, ${ }^{a}$ Xinxiang Zhang, (D) *a \\ Cuixia Chen, ${ }^{a}$ Bo Jiang, (DD ${ }^{\mathrm{b}}$ Hanxian Chen, ${ }^{\mathrm{a}}$ Lianghong Yan ${ }^{\mathrm{c}}$ and Wenbin Yang ${ }^{* \mathrm{~b}}$
}

To control the microstructure and properties of sol-gel silica antireflective (AR) coatings, a simple PMHS (poly(methylhydrogen)siloxane) surface modification method was applied and investigated. This is accomplished simply by immersing the AR coating into the modifier solution containing PMHS, hexane and the Karstedt catalyst and then immediately withdrawing it at a desired withdrawal rate. A systematic study was carried out to investigate the effect of PMHS on the microstructure and optical, hydrophobic and mechanical properties of sol-gel silica AR coatings. It was found that PMHS surface modification greatly increased the hydrophobicity and mechanical properties of sol-gel silica AR coatings by increasing their water contact angles from $27.2^{\circ}$ to about $120^{\circ}$ and Young's modulus from $317 \mathrm{MPa}$ to $482 \mathrm{MPa}$. Most importantly, the transmittance of AR coatings can be tailored well between $96.4 \%$ and $100 \%$ by controlling the PMHS chain length, PMHS concentration and withdrawal rate. Speculation and verification of the PMHS surface modification process was discussed in detail after SEM characterization and optical simulation by TFCalc ${ }^{\text {TM }}$ software. Finally, with this simple method, a hydrophobic sol-gel silica AR coating with excellent transmittance of $99.9 \%$, improved mechanical properties and AR stability was realized, which can find great applications in high power laser fusion systems.

Received 19th April 2017

Accepted 1st June 2017

DOI: $10.1039 / \mathrm{c} 7 \mathrm{ra0} 4400 \mathrm{c}$

rsc.li/rsc-advances coating is porous and polar because it consists of a loose layer of hydrophilic silica particles that are randomly stacked on the optical substrate. Therefore, in the high-powered laser system, the sol-gel silica AR coating tends to absorb polar contaminants such as water and plasticizers of engineering materials from environment. ${ }^{\mathbf{1 7 , 1 8}}$ The pollutants adsorbed in the pores of AR coatings will gradually increase the refractive index and hence decrease the transmittance. In addition, the sol-gel silica AR coatings are kept intact only by point contact forces between individual particles, and therefore the mechanical strength is quite weak. ${ }^{19,20}$

It is very desirable to overcome the poor AR stability of solgel silica AR coating. Because there are thousands of transmissive optics in high-powered laser system, a slight decrease in transmittance of individual optic will significantly decrease the total energy directed into the target chamber. To improve the AR stability of sol-gel silica AR coatings, surface modification, ${ }^{21-25}$ organic-inorganic hybrid (OIH) coatings from tetraethyl orthosilicate (TEOS) and organic precursors ${ }^{26-29}$ and OIH coatings from silica and polymers ${ }^{30-34}$ have been investigated.

The surface modification of sol-gel silica AR coating with hexamethyldisilazane (HMDS) was proposed and applied in National Ignition Facility (NIF). ${ }^{21}$ The HMDS surface modification of sol-gel silica AR coatings involved two steps, the initial treatment with ammonia and water vapor followed by treatment with HMDS. After HMSD surface modification, the hydroxyl groups on the surface of sol-gel silica AR coatings can be 
converted into the hydrophobic $-\mathrm{Si}\left(\mathrm{CH}_{3}\right)_{3}$ groups, and the AR stability can be significantly improved. However, the surface modification is time-consuming. OIH coatings from TEOS and organic precursors were prepared by using TEOS and organic precursors such as methyltrimethoxysilane (MTES) or dimethyldiethoxysilane (DDS) as co-precursors. ${ }^{28}$ The introduction of methyl groups greatly improved the hydrophobicity and hence the AR stability of sol-gel silica AR coatings. However, the "spring-back" phenomenon of hydrophobic groups in the $\mathrm{OIH}$ network would significantly increase the porosity and therefore decrease the refractive index of AR coatings. ${ }^{35}$ As the refractive index of AR coating decreases from 1.23 to 1.10, according to the Freshnel equation of $R=\left(n_{\mathrm{c}}{ }^{2}-n_{\mathrm{s}}\right)^{2} /\left(n_{\mathrm{c}}{ }^{2}+n_{\mathrm{s}}\right)^{2}$, the transmittance decreases from $100 \%$ to $98.3 \%,{ }^{36}$ where $n_{\mathrm{c}}$ and $n_{\mathrm{s}}$ are the refractive index of AR coating and optical substrate. This is disadvantage to high power laser system because the transmittance of transmissive optics should be higher than $99.5 \%$. OIH coatings from silica and polymer were prepared by adding ethanol-soluble polymer (such as polyvinyl butyral (PVB), polyvinyl alcohol (PVA) and polydimethylsiloxane (PDMS) with low molecular weight) into the silica sols. ${ }^{34}$ The increase in AR stability of this method is not as good as the above two methods. Also, the addition of polymer would increase the refractive index, which would also decrease the transmittance of AR coatings.

In our previous study, we reported a novel surface modification method for sol-gel silica AR coatings by using pol$\mathrm{y}$ (methylhydrogen)siloxane (PMHS) as modifier. ${ }^{37}$ It has been demonstrated that the PMHS surface modification could control the transmittance and hydrophobicity of sol-gel silica AR coating. The chemical reaction principle of PMHS surface modification is simple and clear. PMHS chain bears reactive -Si-H groups and amounts of hydrophobic methyl groups. The dehydrogenation reaction occurs between $-\mathrm{Si}-\mathrm{H}$ of PMHS chains and hydroxyl groups on the surface of silica particles. As a result, the quantity of hydroxyl groups decrease and the PMHS chains with low surface energy are grafted onto the AR coating, improving significantly the hydrophobicity and hence the AR stability of sol-gel silica AR coatings. However, the microscopic process of PMHS surface modification is the key factor to control the macro-properties of sol-gel silica AR coating. In this work, a systematical research was carried out to investigate the effect of PMHS on the microstructure, optical, hydrophobic as well as mechanical properties of solgel silica AR coatings. We also discussed the speculation and verification of PMHS surface modification process after SEM characterization and optical simulation by TFCalc ${ }^{\mathrm{TM}}$ software. In addition, this work also characterized quantitatively the nano-mechanical propertied of sol-gel silica AR coating by Bruker atomic force microscope (AFM) using PeakForce QNM scan mode. This is one of the significant contributions of this work to the sol-gel silica AR coating, because the characterization of mechanical properties of sol-gel silica AR coatings in the previous studies is quite qualitative or indirect. ${ }^{17,38,39}$ Most importantly, a systematic investigation was carried out to investigate the effect of PMHS surface modification on microstructure and properties of sol-gel silica AR coatings. Finally, with this simple method, hydrophobic solgel silica AR coating with excellent transmittance of $99.9 \%$, improved mechanical property and AR stability was realized, which can find great application in high power laser fusion system.

\section{Experimental section}

\subsection{Materials}

Tetraethyl orthosilicate (TEOS) was purchased from SigmaAldrich. Ethanol and ammonia water were purchased from Sinopharm Chemical Reagent Co., Ltd. PMHS was purchased from Chengguang Research Institute of Chemical Industry (Chengdu, China). Poly(methylhydrogen)siloxane (PMHS) were named as $0.2 \mathrm{PMHS}$, 1.0PMHS and 1.5PMHS as the hydrogen content is $0.2 \%, 1.0 \%$ and $1.5 \%$, respectively.

\subsection{Preparation of silica sol and AR coating}

17.9 $\mathrm{mL}$ TEOS, $175 \mathrm{~mL}$ ethanol, $4 \mathrm{~mL} \mathrm{H}_{2} \mathrm{O}$ and $1.0 \mathrm{~mL} \mathrm{NH}_{3} \cdot \mathrm{H}_{2} \mathrm{O}$ was added into a $250 \mathrm{~mL}$ flask and then stirred for $2 \mathrm{~h}$ at $30^{\circ} \mathrm{C}$. The resultant sol was aged at $25{ }^{\circ} \mathrm{C}$ for 9 days. Before coating, the sol was carefully filtered through $0.22 \mu \mathrm{m}$ PVDF filters. The BK7 glasses were cleaned with ethanol and then wiped carefully with cleanroom wipers. Finally, the silica AR coatings were coated onto the cleaned BK7 glass by dip-coating at the withdrawal rate of $100 \mathrm{~mm} \mathrm{~min}^{-1}$. The AR coatings were heated at $160{ }^{\circ} \mathrm{C}$ for $2 \mathrm{~h}$.

\subsection{Surface modification of silica AR coatings}

0.2PMHS, 1.0PMHS and 1.5PMHS were applied as modifier. Modifier solutions with PMHS contents of $0.00 \%, 0.25 \%$, $0.50 \%, 1.00 \%$ and $1.50 \%$ were obtained by mixing PMHS, hexane, and Karstedt catalyst (platinum-1,3-divinyl-1,1,3,3tetramethyldisiloxane) together. The content of Pt in modifier solution is about $20 \mathrm{ppm}$. The surface modification process is accomplished by dipping the silica AR coating into the modifier solutions and then immediately withdrawing out at the withdrawal rate of $50 \mathrm{~mm} \mathrm{~min}^{-1}$ and $100 \mathrm{~mm} \mathrm{~min}^{-1}$, respectively. The PMHS modified silica AR coatings were heated at $160{ }^{\circ} \mathrm{C}$ for $2 \mathrm{~h}$.

\subsection{Characterization}

The transmittance spectra were recorded with a UV-Vis spectrophotometer (Mapada, 3200). The theoretical transmittance spectra were modeled by TFCalc ${ }^{\mathrm{TM}}$ software (Nanjing Wavelab Software System Co. Ltd.). The water contact angles of the AR coatings were measured on Krüss DSA100. The cross-section SEM was performed using a SU8010 high-resolution SEM (Hitachi). The surface morphology, adhesion force and Young's modulus were characterized by Bruker atomic force microscope (AFM) using PeakForce QNM scan mode, in which the quantitative nano-mechanical properties can be mapped. The probe is TAP150A. 


\section{Results and discussion}

\subsection{Effect of PMHS surface modification on optical} properties

For high-powered laser fusion system, a feasible surface modification strategy of sol-gel silica AR coating should meet two requirements. One the one hand, the surface modification should not decrease the transmittance of modified AR coatings. The transmittance of AR coating in high power laser system should be nearly $100 \%$ (commonly higher than $99.5 \%$ ). There are thousands of transmissive optics in high power laser system. According to eqn (1), ${ }^{36}$ each optical component creates optical reflection at the air-components surfaces. The optical reflection will not only confuse the target diagnostic but also obviously reduce the out putenergy. One the other hand, the surface modification should also not change the optical thickness obviously. AR coating used in high power laser system should have desired optical thickness $\left(n_{\mathrm{c}} d\right)$ because, according to eqn (2), ${ }^{36}$ it determines the central wavelength. As the central wavelength is near to the wavelength of laser, the AR coating possesses the maximum transmittance. As the surface modification changes optical thickness obviously, the wavelength of maximum transmittance $\left(\lambda_{0}\right)$ will red-shifted obviously, which will significantly decrease the transmittance at the wavelengths of lasers.

$$
\begin{gathered}
\lambda_{0}=4 n_{\mathrm{c}} d \\
R=\left(n_{\mathrm{c}}{ }^{2}-n_{\mathrm{s}}\right)^{2} /\left(n_{\mathrm{c}}{ }^{2}+n_{\mathrm{s}}\right)^{2}=(1-T) / 2
\end{gathered}
$$

where $n_{\mathrm{c}}$ and $n_{\mathrm{s}}$ is the refractive index of AR coating and substrate, $d$ is the physical thickness of AR coating, and $R$ and $T$ is the reflection and transmittance of AR coating.

The effect of hydrogen content of PMHS, PMHS content in modifier solution and withdraw rate on the optical properties of
AR coating was systematically investigated by a UV-Vis spectrophotometer. The transmittance spectra were shown in Fig. 1. The values of central wavelength and maximum transmittance at central wavelength were read from Fig. 1, and listed in Table 1. For 0.2PMHS modified AR coatings, at the withdraw rate of 50 and $100 \mathrm{~mm} \mathrm{~min}^{-1}$, the PMHS content has little effect on the central wavelength and the transmittance. As the PMHS content increased from $0.00 \%$ to $1.50 \%$, the central wavelength increases slightly from $783 \mathrm{~nm}$ to $810 \mathrm{~nm}$ and from $783 \mathrm{~nm}$ to $808 \mathrm{~nm}$, respectively, and the transmittance is almost unchanged (nearly 100\%). For 1.5PMHS modified AR coatings, the PMHS content significantly affects the optical property of AR coatings. As shown in Fig. 2(e) and (f), the transmittance spectra were quite different as the PMHS content increased from $0.00 \%$ to $1.50 \%$. At withdraw rate of $50 \mathrm{~mm} \mathrm{~min}^{-1}$, the central wavelength of 1.5PMHS modified AR coatings increased from $783 \mathrm{~nm}$ to $1073 \mathrm{~nm}$, and the transmittance decreased from $100 \%$ to $96.4 \%$. Finally, it can be concluded that the 0.2 PMHS is the best candidate for surface modification of AR coating used in high power laser system.

\subsection{Speculation and verification of PMHS surface modification process}

As discussed before, the hydrogen content of PMHS and PMHS content in the modifier solution affected the optical properties of AR coating. To speculate the PMHS surface modification process, the chemical structure and the microstructure of the sol-gel silica AR coating should be took into account.

3.2.1 Chemical reaction during PMHS surface modification. As shown in Fig. 2(a), PMHS is a polymer with the general structure of $-\left[\mathrm{CH}_{3} \mathrm{Si}(\mathrm{H})-\mathrm{O}\right]_{m}-\left[\left(\mathrm{CH}_{3}\right)_{2} \mathrm{Si}-\mathrm{O}\right]_{n}{ }^{-}$. PMHS molecule contains reactive $\mathrm{Si}-\mathrm{H}$ bonds and amounts of hydrophobic $-\mathrm{CH}_{3}$ groups. The $\mathrm{Si}-\mathrm{H}$ bonds can participate in a variety of chemical reactions especially with vinyl alkenyl compounds and
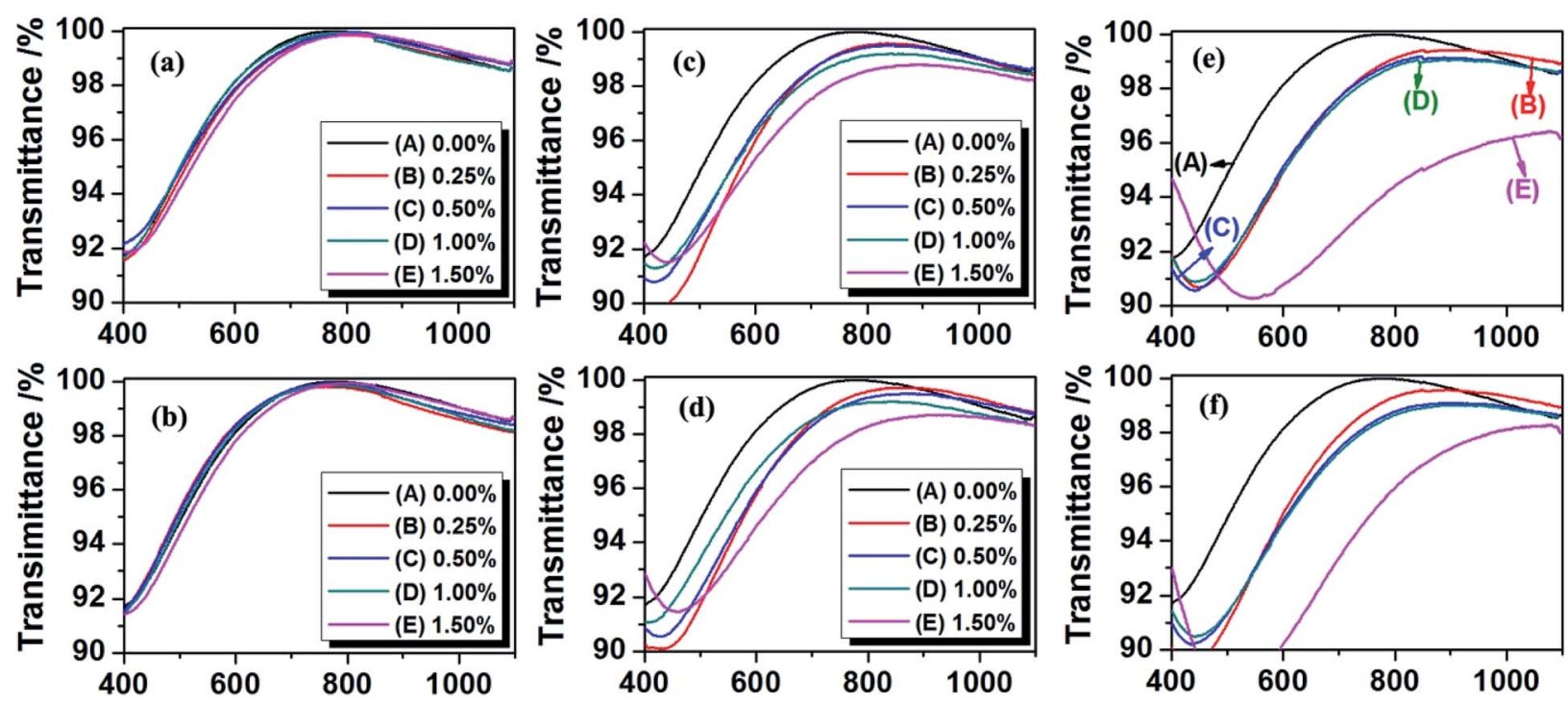

Fig. 1 Effect of withdraw rate and PMHS content on the transmittance of AR coatings (0.2PMHS: (a) and (b); 1.0PMHS: (c) and (d); 1.5PMHS: (e) and (f); $50 \mathrm{~mm} \mathrm{~min}^{-1}$ : (a), (c) and (e); $100 \mathrm{~mm} \mathrm{~min}^{-1}$ : (b), (d) and (f).). 
Table 1 Central wavelength and transmittance at central wavelength of 0.2PMHS, 1.0PMHS and 1.5PMHS modified AR coatings with different withdraw rate and $\mathrm{PMHS}$ concentration

\begin{tabular}{|c|c|c|c|c|c|c|c|c|c|c|c|c|}
\hline \multirow{2}{*}{$\begin{array}{l}\text { Coating speed } \\
n_{\mathrm{c}} d^{a} \text { and } T^{a} \\
\end{array}$} & \multicolumn{2}{|c|}{$50 \mathrm{~mm} \mathrm{~min}^{-1}$} & \multicolumn{2}{|c|}{$\begin{array}{l}100 \mathrm{~mm} \\
\mathrm{~min}^{-1}\end{array}$} & \multicolumn{2}{|c|}{$50 \mathrm{~mm} \mathrm{~min}^{-1}$} & \multicolumn{2}{|c|}{$\begin{array}{l}100 \mathrm{~mm} \\
\mathrm{~min}^{-1}\end{array}$} & \multicolumn{2}{|c|}{$50 \mathrm{~mm} \mathrm{~min}^{-1}$} & \multicolumn{2}{|c|}{$100 \mathrm{~mm} \mathrm{~min}-1$} \\
\hline & ncd & $T$ & ncd & $T$ & $\lambda_{0}$ & $T$ & $\lambda_{0}$ & $T$ & $\lambda_{0}$ & $T$ & $\lambda_{0}$ & $T$ \\
\hline $0.00 \%$ & 783 & 100 & 783 & 100 & 783 & 100 & 783 & 100 & 783 & 100 & 783 & 100 \\
\hline $1.00 \%$ & 799 & 99.9 & 756 & 99.9 & 841 & 99.2 & 841 & 99.2 & 905 & 99.1 & 903 & 99.0 \\
\hline $1.50 \%$ & 810 & 99.9 & 808 & 99.9 & 892 & 98.8 & 921 & 98.7 & 1073 & 96.4 & 1047 & 98.2 \\
\hline
\end{tabular}

(a)

PMHS:<smiles>CC(C)(C)O[Si](C)(C)C</smiles><smiles>CC(C)(C)O[Si](C)(C)C</smiles><smiles>CC1(C)O[Si](C)(C)C1(C)O[Si](C)(C)C</smiles>

(b) Silica:
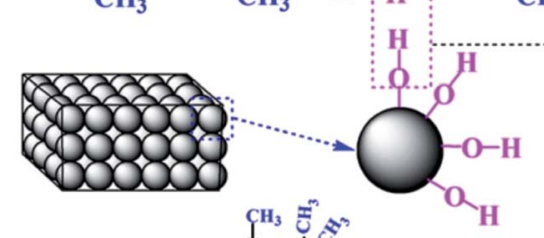

hydroxyl compounds. As shown in Fig. 2(b), the sol-gel AR coatings consist of a layer of silica particles that are randomly stacked on the substrate's surface. The individual silica particles' surface was covered by hydroxyl groups. In addition, Karstedt catalyst is the complex compound of platinum and 1,3divinyl-1,1,3,3-tetramethyldisiloxane, which has very high catalytic activity. Therefore, in the presence of Karstedt catalyst, the reaction between $\mathrm{Si}-\mathrm{H}$ of PMHS and $\mathrm{Si}-\mathrm{OH}$ of silica particles happens immediately at room temperature, which had been demonstrated by FTIR in our previous work. Surface modification of silica AR coating can be easily realized by immerging the AR coatings into the modifier solution which contains PMHS and Karstedt catalyst.

3.2.2 Penetration and anti-penetration during PMHS surface modification. Penetration and anti-penetration of PMHS is the key factor to control the microstructure and therefore the optical properties of sol-gel silica AR coating. As shown in Fig. 3(a), the sol-gel silica AR coating is porous because it is consisted randomly of a layer of silica particles. It is the porous property affords sol-gel silica AR coating excellent transmittance of $100 \% .{ }^{17}$ According to eqn (2), the refractive index of AR coating should be 1.23 to give $100 \%$ transmittance for glass substrate $\left(n_{\mathrm{s}}=1.52\right)$. However, the refractive index of dense silica thin film is 1.46 . The refractive index of thin film can be lower by incorporating nano-pores into the thin film because it is related to the porosity according to the LorentzLorenz equation: ${ }^{40}$

$$
\text { Porosity }=1-\left(n^{2}-1\right) /\left(n_{\mathrm{d}}^{2}-1\right)
$$

where $n$ is the refractive index of porous silica AR coating and $n_{\mathrm{d}}$ is the refractive index of dense silica thin film.

PMHS is a polymer in the form of flexible chain. The difference between the pore size and the chain length of PMHS is the key factor to predict whether the PMHS chains play a role of penetration or anti-penetration. Our previous study indicated that the average pore radius of sol-gel silica from nitrogen adsorption/desorption analysis is about $2.6 \mathrm{~nm}$, which indicates the pore diameter of sol-gel silica AR coating is about $5.2 \mathrm{~nm}^{41}$

The theoretical molecule weight of 0.2PMHS, 1.0PMHS and 1.5PMHS is calculated to be about 12036,2416 and 1602 , respectively, and then the length of extended chains is estimated to be about $47 \mathrm{~nm}, 10 \mathrm{~nm}$ and $7 \mathrm{~nm}$, respectively. (See ESI: $\dagger$ theoretical calculation of molecule weight and estimation of chain length of PMHS). Actually, the flexibility of PMHS is good, and it would be in the manner of random coil nor extended chain in good solvent. The size of PMHS coil is much smaller than the estimated ones. Therefore, a schematic representation of microstructure change of AR coating before and after PMHS surface modification can be drew as Fig. 3 and contrasted with the SEM images.

Because the size of 1.5PMHS coil is smaller than that of pores in AR coating, the 1.5PMHS can penetrate fast into the pores. After the air in the pores being replaced by the PMHS, the refractive index of AR coating increased. With the increasing PMHS content in the modifier solution, more PMHS chains aggregated in the pore of AR coating, and the increment of refractive index is more remarkable. This explained well the significant change in optical properties of 1.5\%PMHS modified AR coating as a function of PMHS content: (1) according to eqn (1), the apparent increase in optical thickness $\left(n_{\mathrm{c}} d\right)$ resulted in the red-shift of central wavelength; and (2) according to eqn (2), the bigger refractive index a thin film is, the smaller transmittance will be. 

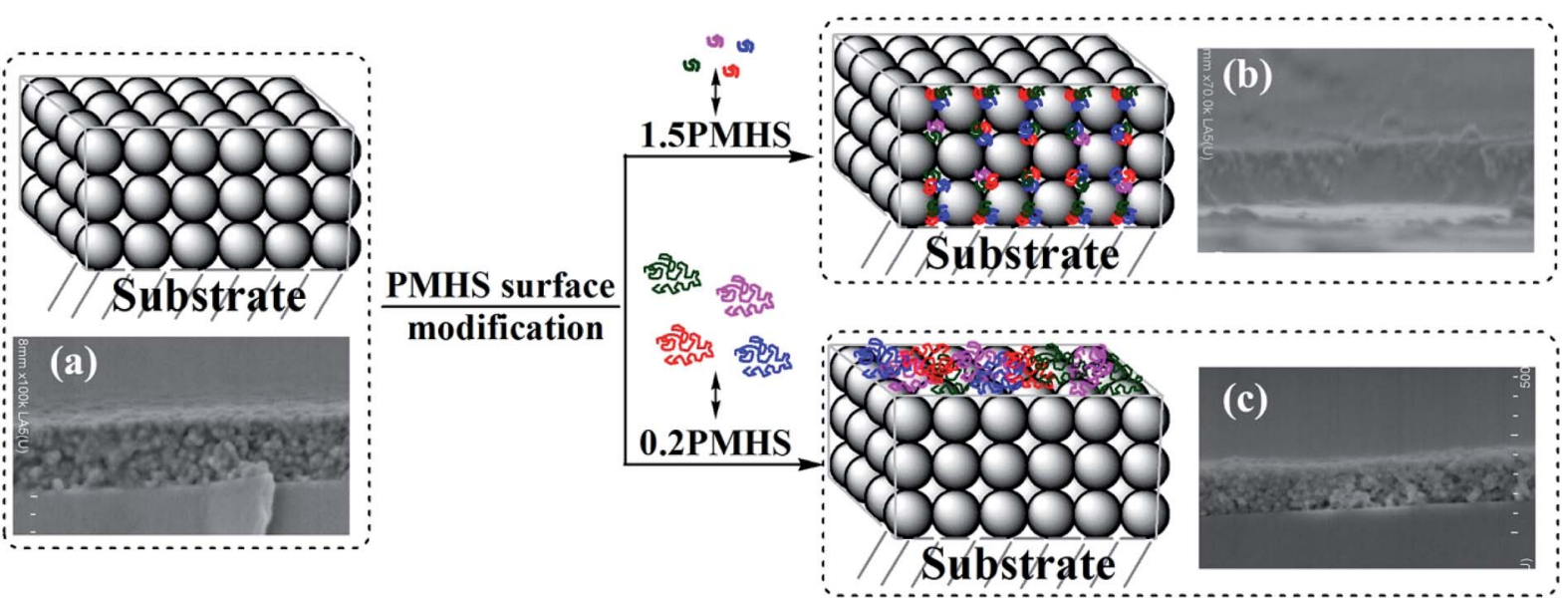

Fig. 3 Schematic representation and cross-sectional SEM images of AR coating before and after PMHS surface modification (unmodified (a), 1.5PMHS modified (b) and 0.2PMHS modified (c) AR coatings).

The size of $0.2 \mathrm{PMHS}$ coil is much bigger than that of pores in AR coating. The flexibility of PMHS chain is very good, and the PMHS coil would penetrate into the pores of AR coating slowly by internal rotation. However, with the Karstedt catalyst, the reaction between the $-\mathrm{Si}-\mathrm{H}$ of $0.2 \mathrm{PMHS}$ and $-\mathrm{Si}-\mathrm{OH}$ on the surface of AR coating is ultra-fast at room temperature. As shown in Fig. 3(b), the big 0.2PMHS coil will graft immediately onto adjacent silica particles after the sol-gel silica AR coating being immerged into the modifier solution. The $0.2 \mathrm{PMHS}$ surface modification weaves a web on the surface of AR coating, and the more 0.2PMHS chains cannot penetrate into the pores. The PMHS web is very benefit to maintain the porous property. As shown in Fig. 1(a) and (b), 0.2PMHS content as well as the withdraw rate have little effect on the optical transmittance of AR coating. This is because the very thin web weaved on the surface hinders the more 0.2PMHS from penetrating into the pore of AR coating or aggregating on the surface of AR coating.

3.2.3 Verification of PMHS surface modification by SEM. The PMHS surface modification of sol-gel silica AR coating was speculated based on the pore size of AR coating, coil size of PMHS as well as the reactivity of PMHS. The speculation of PMHS surface modification process explained well the effect of PMHS on the optical properties of AR coating. To verify the speculation, the cross-sectional SEM images of unmodified, 1.5PMHS modified and 0.2PMHS modified AR coatings were characterized. As shown in Fig. 3(a), the sol-gel silica AR coating is consisted of a layer of silica particles which were randomly stacked onto the substrate, and therefore it is porous. Fig. 3(b) represents a rather dense cross-section of AR coating after being immerging into modifier solution with high 1.5PMHS content. This is in good agreement with the speculation, in which the 1.5PMHS penetrated into the pores of AR coating and replaced the air in the pores. Cross-sectional SEM image of 0.2PMHS modified AR coating verifies that few 0.2PMHS penetrates into the pores, and 0.2PMHS surface modification does not significantly affect the microstructure of porous AR coating.

3.2.4 Verification of PMHS surface modification by optical simulation. In addition to verify the speculation of PMHS surface modification process by SEM, an optical simulation of AR coating by TFCalc ${ }^{\mathrm{TM}}$ software was carried out. For PMHS surface modification of porous sol-gel silica AR coatings, two models were built for verification the change in optical property as shown in Fig. 1 and Table 1. As shown in Fig. 4, in Model 2, the PMHS chains penetrated into the pores of AR coating, the penetrating thickness maybe related to the PMHS content, PMHS chain length and withdraw rate. In Model 1, the PMHS did not penetrate into the pores and hence aggregated onto the surface of AR coating. For both of Model 1 and Model 2, the PMHS modified AR coatings were separated into two individual new coatings, the blue one and the black-and-white (B\&W) one. The $\mathrm{B} \& \mathrm{~W}$ one has the refractive index of 1.23 , while the blue one has a much higher refractive index. 0.2PMHS and 1.5PMHS modified AR coatings with withdraw rate of $50 \mathrm{~mm} \mathrm{~min}^{-1}$ were chose to calculate the film parameters for Model 1 and Model 2. In this calculation, two assumptions are involved: first, that the refractive index of the new formed coating (the blue one) is set to be 1.4 (the same as that of PMHS oil), and second, that the optical thickness of modified AR coating is the summary of optical thickness of two individual coatings (blue one and B\&W one).

For 0.2PMHS modified AR coating, the central wavelength increased from $783 \mathrm{~nm}$ to $810 \mathrm{~nm}$ as the PMHS content increase from $0.00 \%$ to $1.50 \%$. In Model 1 of $0.2 \mathrm{PMHS}$ modified AR coating, the physical thickness for B\&W layer $\left(d_{1}\right)$ is equal to that of unmodified AR coating, which is $159.2 \mathrm{~nm}$. Submitting $n_{1}=$ 1.23 and $n_{2}=1.40$ into the following equation:

$$
n_{1} d_{1}+n_{2} d_{2}=810 / 4 \mathrm{~nm}
$$

We get the physical thickness of the blue layer $\left(d_{2}=4.8 \mathrm{~nm}\right)$.

In Model 2 of 0.2PMHS modified AR coating, the total physical thickness and optical thickness is $159.2 \mathrm{~nm}$ and $202.5 \mathrm{~nm}\left(\lambda_{0} / 4\right)$. So, there are two equations as following.

$$
d_{3}+d_{4}=159.2 \mathrm{~nm}
$$




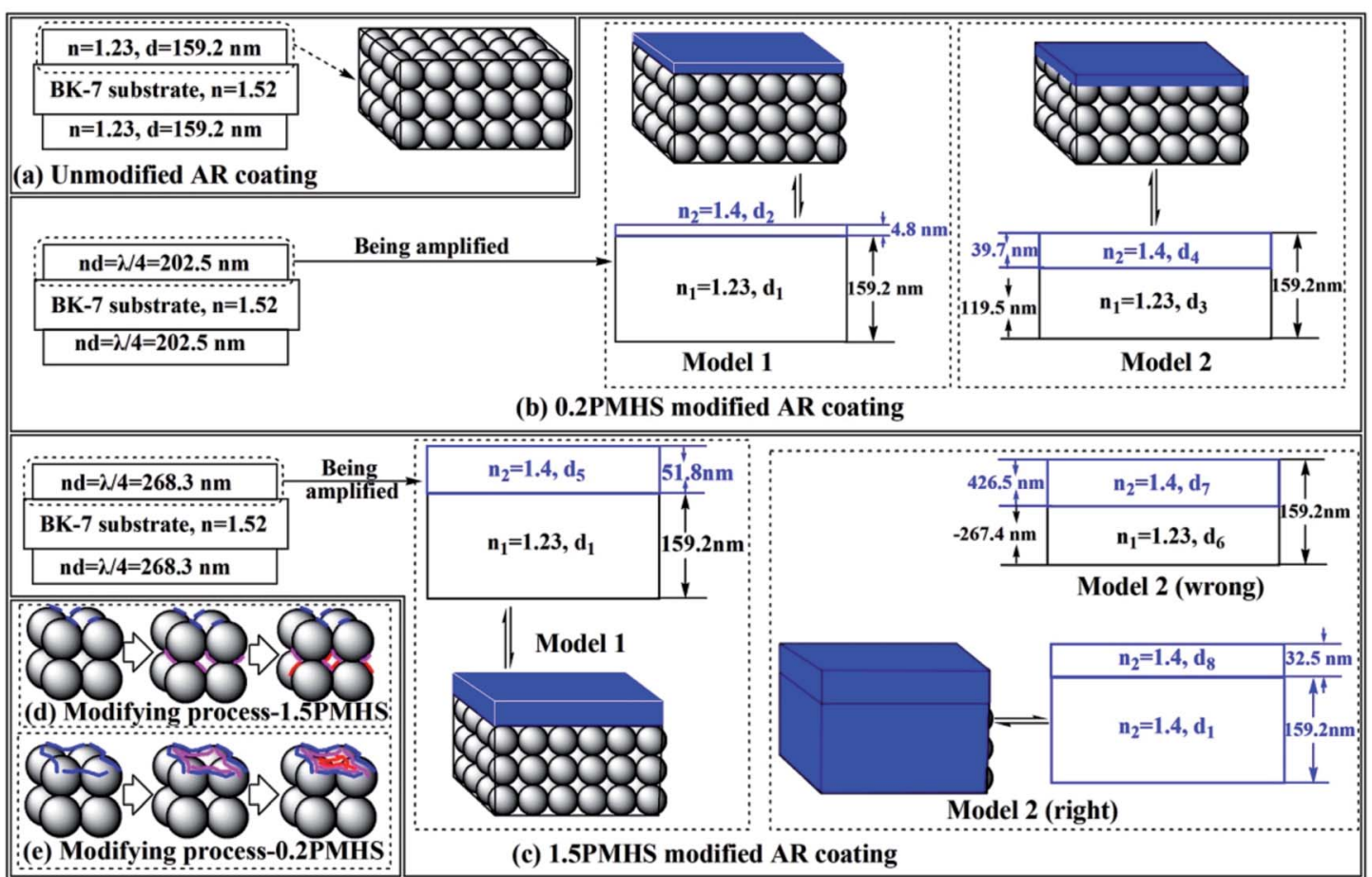

Fig. 4 Schematic representation of PMHS surface modification process ((a) unmodified AR coating; (b) 0.2PMHS modified AR coating; (c) 1.5PMHS modified AR coating; (d) and (e) modifying processes of 1.5PMHS and 0.2PMHS modified AR coating).

$$
n_{1} d_{2}+n_{2} d_{4}=810 / 4 \mathrm{~nm}
$$

From the above two equations, we get the physical thickness of the B\&W layer and blue layer $\left(d_{3}=119.5 \mathrm{~nm}, d_{4}=39.7 \mathrm{~nm}\right)$.

For 1.5PMHS modified AR coating, the central wavelength increased from $783 \mathrm{~nm}$ to $1073 \mathrm{~nm}$ as the PMHS content increase from $0.00 \%$ to $1.50 \%$. In Model 1 of 1.5 PMHS modified AR coating, the physical thickness for B\&W layer $\left(d_{1}\right)$ is also equal to that of unmodified AR coating, which is $159.2 \mathrm{~nm}$.

Submitting $n_{1}=1.23$ and $n_{2}=1.40$ into the following equation:

$$
n_{1} d_{1}+n_{2} d_{5}=1073 / 4 \mathrm{~nm}
$$

We get the physical thickness of the blue layer $\left(d_{5}=51.8\right.$ $\mathrm{nm})$.

In Model 2 of 1.5PMHS modified AR coating, the total physical thickness and optical thickness is $159.2 \mathrm{~nm}$ and $268.3 \mathrm{~nm}\left(\lambda_{0} / 4\right)$. So, there are two equations as following.

$$
\begin{gathered}
d_{6}+d_{7}=159.2 \mathrm{~nm} \\
n_{1} d_{6}+n_{2} d_{7}=1073 / 4 \mathrm{~nm}
\end{gathered}
$$

We get the physical thickness of the B\&W layer and blue layer from eqn (8) and (9) ( $\left.d_{6}=-267.4 \mathrm{~nm}, d_{7}=426.5 \mathrm{~nm}\right)$. The value of film thickness of $\mathrm{B} \& \mathrm{~W}$ layer is negative, which indicate that the Model 2 for 1.5PMHS modified AR coating is wrong. The other possibility for Model 2 is that all of pores in AR coating were filled with PMHS chains and there is an additional coating formed on the surface as shown in Fig. 4(c). So, the refractive index of the whole modified AR coating is 1.40, and there are eqn (10) for the right Model 2.

$$
n_{2}\left(d_{1}+d_{8}\right)=1073 / 4 \mathrm{~nm}
$$

From eqn (9), we get the physical thickness of the whole AR coating $\left(\left(d_{1}+d_{8}\right)=191.6 \mathrm{~nm}\right)$.

Finally, the refractive index and physical thickness of Model 1 and Model 2 for 0.2PMHS and 1.5PMHS modified AR coatings were calculated and the results were shown in Fig. 4. By inputting the refractive index and physical thickness of these four simulated AR coating into the TFCalc ${ }^{\mathrm{TM}}$ software, the theoretical transmittance spectra of them were obtained and compared with the experimental transmittance spectra of 0.2PMHS and 1.5PMHS modified AR coatings. As shown in Fig. 5(a), for 0.2PMHS modified AR coating, the experimental transmittance spectrum is in accordance with modeled transmittance spectrum of Model 1; and according to the Fig. 5(b), for 1.5PMHS modified AR coating, the experimental transmittance spectrum is more similar to the modeled transmittance spectrum of Model 2. These indicate that, during modifying process, the $0.2 \mathrm{PMHS}$ chains tend to aggregate onto the surface of AR coating while the 1.5PMHS chains prefer to penetrate into the pores of AR coating. This is in good accordance with the above discussion.

The SEM images combined with the simulation results demonstrate that the microstructure and hence the optical property of sol-gel silica AR coating can be controlled by using PMHS with different chain length. For the sol-gel silica AR 

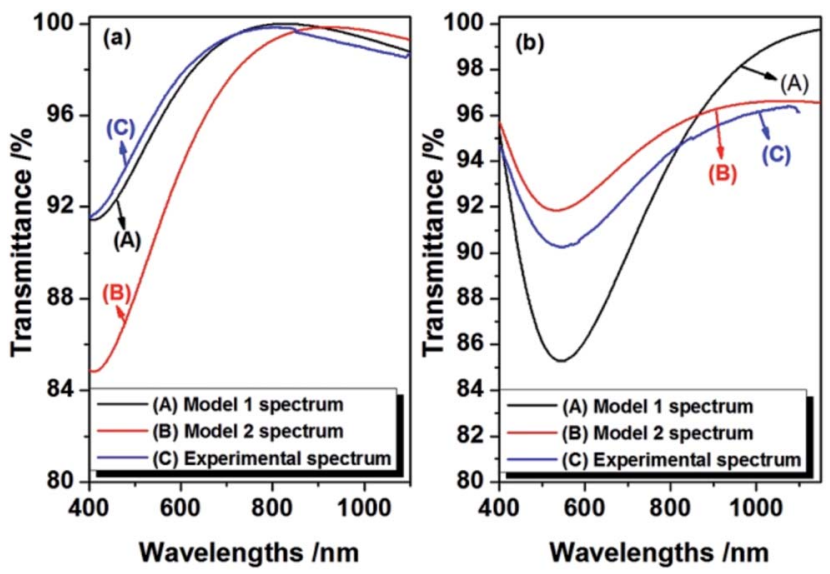

Fig. 5 Experimental and theoretical transmittance spectra of 0.2PMHS (a) and 1.5PMHS (b) modified AR coatings.

coating used in high power laser system, 0.2PMHS is a good modifier.

\subsection{Hydrophobicity and AR stability}

Another important property of AR coating is the hydrophobicity. With increasing hydrophobicity, the AR stability can be significantly improved..$^{42}$ The aim of this work is to improve the hydrophobicity of silica AR coating by PMHS surface modification and hence to improve its AR stability. The hydrophobicity can be represented by the water contact angle. ${ }^{43,44}$ As shown in Fig. 6, the water contact angle of unmodified silica AR coatings is only $27.2^{\circ}$, which indicating that it is hydrophilic. For $0.2 \mathrm{PMHS}$ modified AR coating, the water contact angle increased gradually with PMHS content. As the 0.2PMHS content in modifier solution increases from $0.00 \%$ to $1.50 \%$, the water contact angle of $0.2 \mathrm{PMHS}$ modified AR coating increases from $27.2^{\circ}$ to about $115^{\circ}$. Surprisingly, as the PMHS content in modifier solution increases only from $0.00 \%$ to $0.25 \%$, the water contact angle of 1.5PMHS modified AR coatings increases

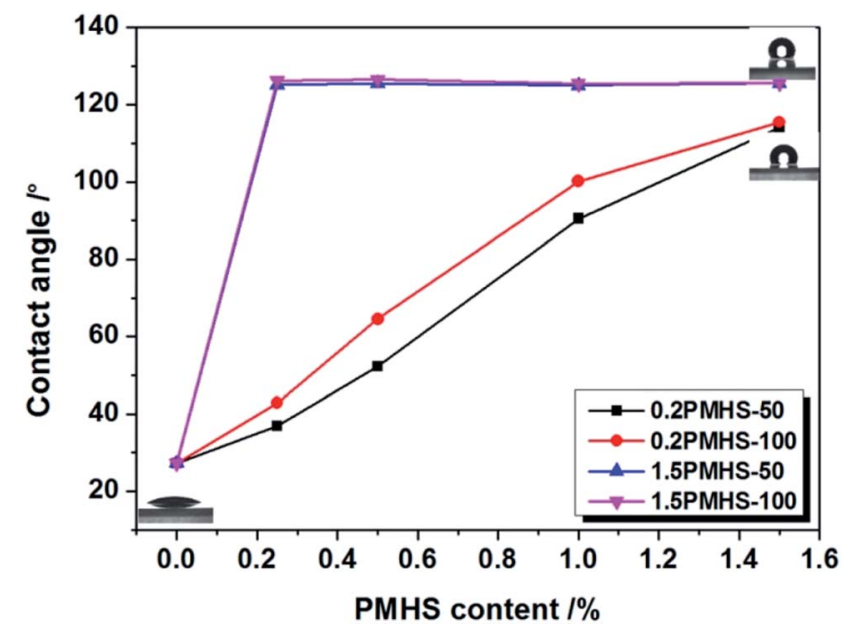

Fig. 6 Effect of withdraw rate and PMHS content on the water contact angles of AR coatings. immediately from $27.2^{\circ}$ to about $125^{\circ}$; and as the PMHS content continue to increase from $0.25 \%$ to $1.50 \%$, the water contact angle of 1.5PMHS modified AR coatings is almost the same. The general formula of PMHS is shown in Fig. 2(a). 1.5PMHS is the concentrated hydrogen silicone oil, in which there is no $-\mathrm{Si}\left(\mathrm{CH}_{3}\right)_{2} \mathrm{O}$ - unit. Therefore, during PMHS surface modification process, 1.5PMHS would remove more $-\mathrm{Si}-\mathrm{OH}$ groups on the surface of silica particles. However, for 0.2PMHS, in addition to the $-\mathrm{SiCH}_{3}(\mathrm{H})-\mathrm{O}-$ units, there are also about $140-\mathrm{Si}\left(\mathrm{CH}_{3}\right)_{2} \mathrm{O}-$ units. These $-\mathrm{Si}\left(\mathrm{CH}_{3}\right)_{2} \mathrm{O}-$ units would not only reduce the density of $-\mathrm{Si}-\mathrm{H}$ groups but also shield the $-\mathrm{Si}-\mathrm{OH}$ on the surface of AR coating and slow down the reaction rate of PMHS and $-\mathrm{Si}-\mathrm{OH}$. So, as the AR coating were dipped into the modifier solution with very low 0.2PMHS content and drawing immediately, there are still many $-\mathrm{Si}-\mathrm{OH}$ on the surface of silica $\mathrm{AR}$ coating. The increasing content of $0.2 \mathrm{PMHS}$ is benefit for surface hydrophobic modification.

In summary, the 1.5PMHS modified AR coatings possess a little bit better hydrophobicity than 0.2PMHS modified AR coating. However, after taking transmittance into account, 0.2PMHS is still the best candidate for surface hydrophobic modification of sol-gel silica AR coating. As the PMHS content in modifier solution is $1.50 \%$ and the withdraw rate is $100 \mathrm{~mm}$ $\mathrm{min}^{-1}$, the water contact angle of $0.2 \mathrm{PMHS}$ modified AR coating is $115.5^{\circ}$ while its transmittance is $99.9 \%$.

AR stability of pure and 0.2PMHS modified silica AR coatings were tested by keeping them in a closed container with 95\% relative humidity at room temperature for 1 month. Fig. 7 shows the maximum transmittance of pure and 0.2PMHS modified silica AR coatings before and after one-month test. The maximum transmittance of pure silica AR coating decreases from $100.0 \%$ to $98.4 \%$, while that of $0.2 \mathrm{PMHS}$ modified silica AR coating decreases from $99.9 \%$ to $99.5 \%$. This indicates that the AR stability of sol-gel silica AR coating is obviously improved after PMHS surface modification. This is attributed to the introduction of amounts of hydrophobic methyl groups into the sol-gel silica AR coating.

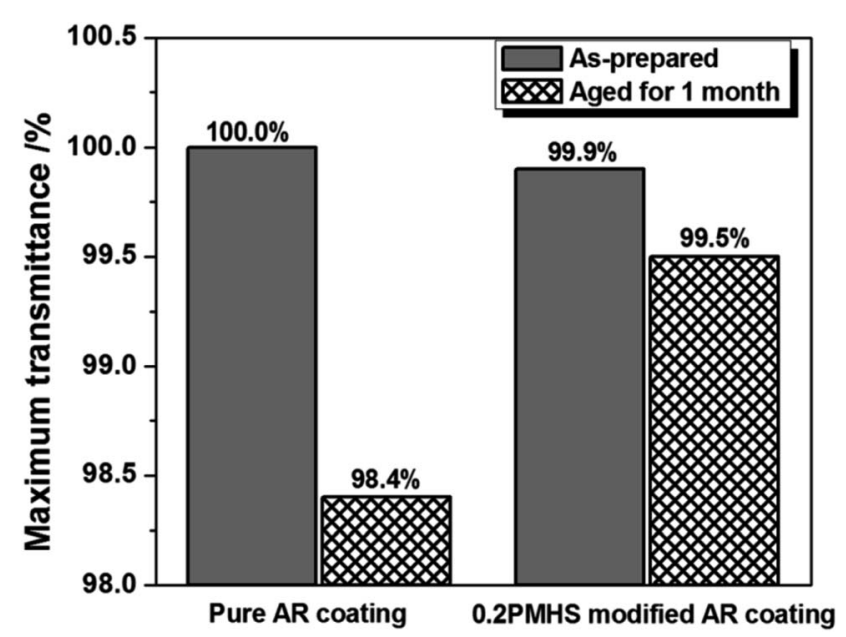

Fig. 7 Change in maximum transmittance of pure and 0.2PMHS modified AR coating before and after one-month test. 


\subsection{Surface morphology}

PMHS surface modification may change the surface morphology of silica AR coating. It has been demonstrated that $0.2 \mathrm{PMHS}$ is the best modifier for sol-gel silica AR coatings. Therefore, the surface morphologies of AR coatings modified by 0.2PMHS solutions with PMHS content of $0.00 \%, 0.50 \%, 1.00 \%$ and $1.50 \%$ were analyzed by atomic force microscopy (AFM). Fig. 8 shows that the $0.2 \mathrm{PMHS}$ surface modification of AR coating did not significantly affect the surface morphologies. As the PMHS content increased from $0.00 \%$ to $1.50 \%$, the roommean-square (RMS) roughness $\left(R_{\mathrm{q}}\right)$ decreased slightly from $6.95 \mathrm{~nm}$ to $5.76 \mathrm{~nm}$. This indicated that the PMHS surface modification did not obviously affect the roughness of sol-gel silica AR coatings. The low roughness would prevent the AR coatings from suffering light scattering. ${ }^{32}$ In addition, the adhesion forces between probe of AFM and 0.2PMHS modified AR coatings were also recorded by AFM. The adhesion forces decrease from $2.21 \mathrm{nN}$ to $0.98 \mathrm{nN}$ as the PMHS content
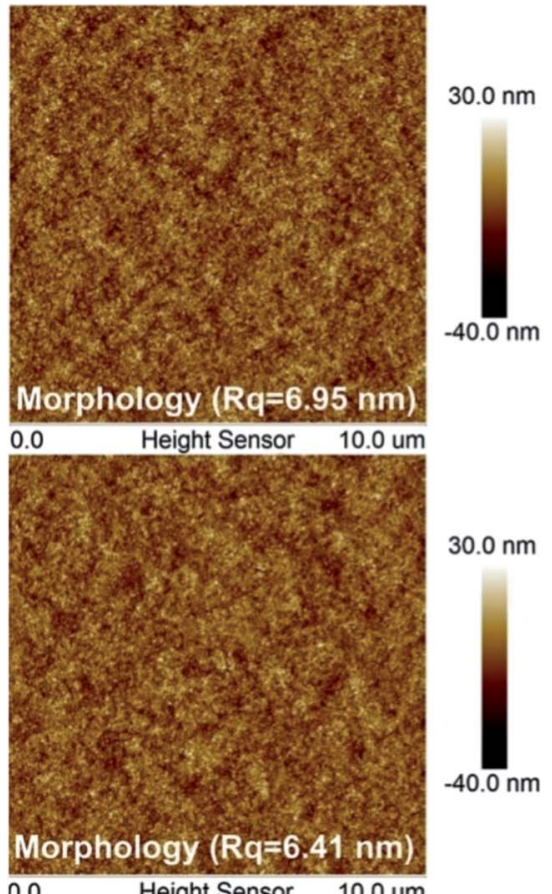

0.0 Height Sensor 10.0 um
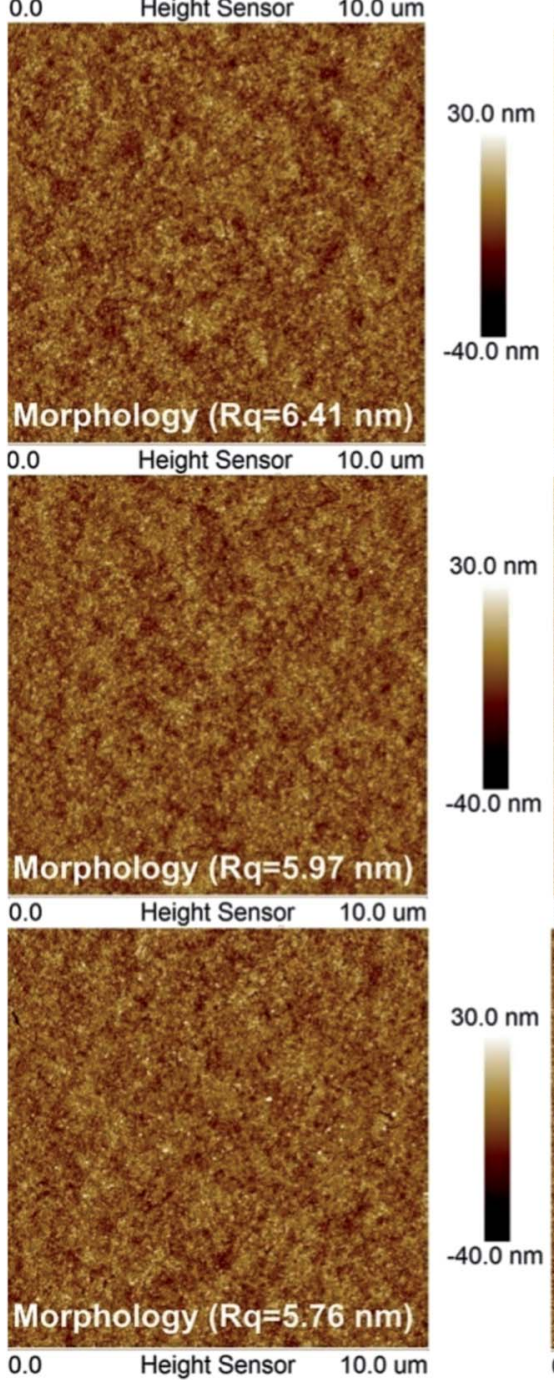
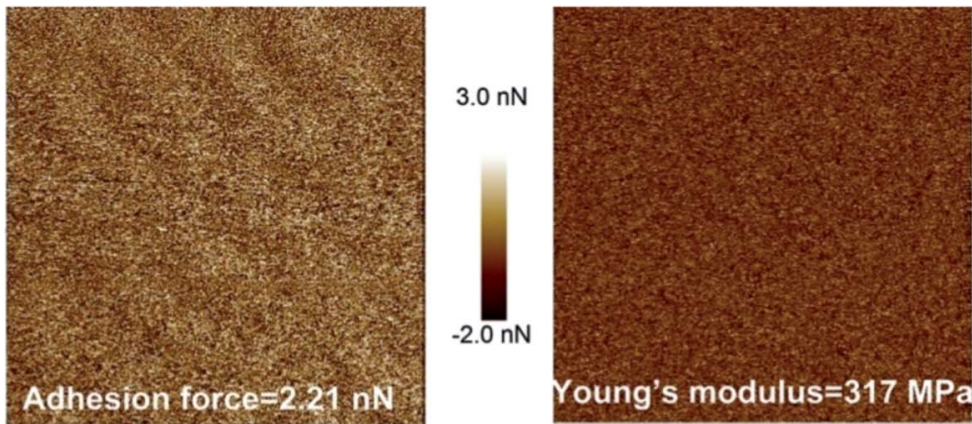

$1.0 \mathrm{GPa}$ 0.0 Adhesion

10.0 um

$$
0.0
$$

DMTModulus

10.0 um

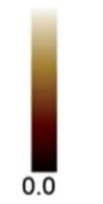

$3.0 \mathrm{nN}$
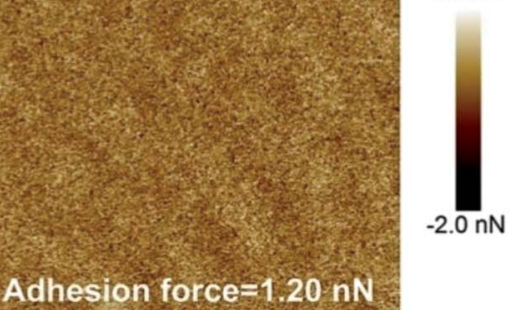

\section{0}

Adhesion

$10.0 \mathrm{um}$
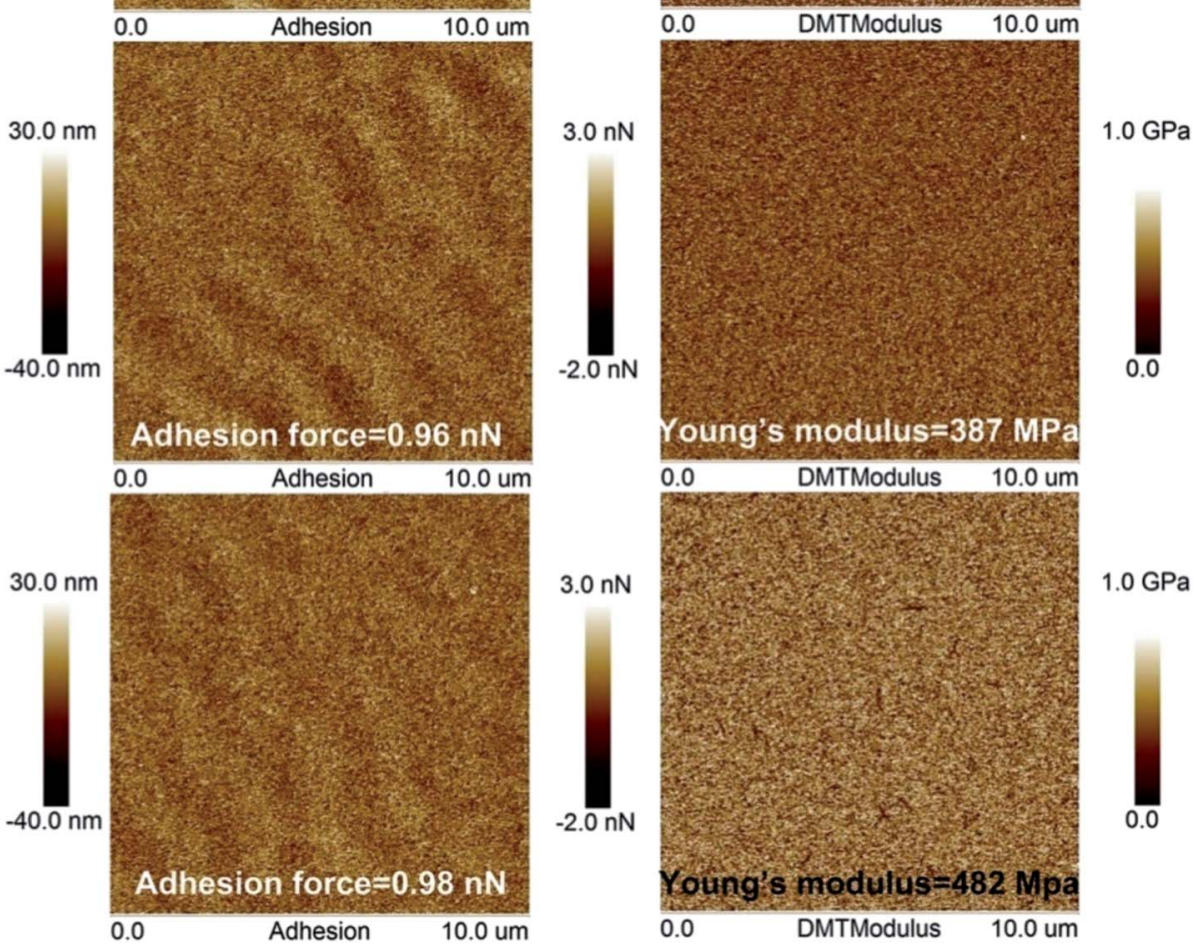

roung's modulus $=387 \mathrm{MPa}$

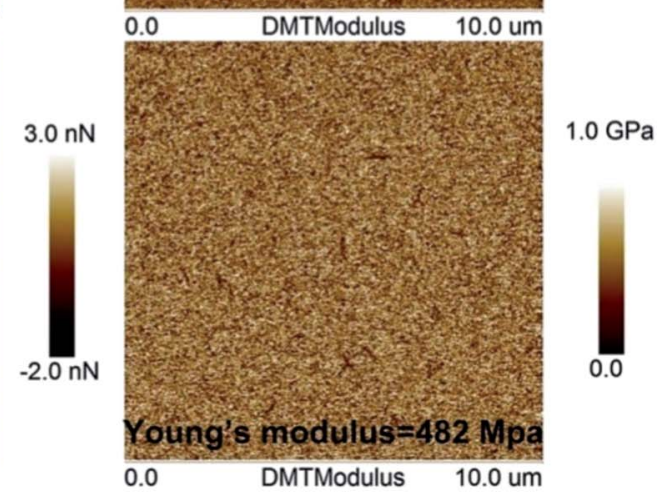

Fig. 8 Effect of PMHS content on the surface morphology, adhesion forces and Young's modulus and of 0.2PMHS modified AR coatings. 
increases from $0.00 \%$ to $1.50 \%$. This is in very good agreement with the results from water contact angles. By increasing the PMHS content from $0.00 \%$ to $1.50 \%$, the water contact angle of 0.2 PMHS modified AR coating with $100 \mathrm{~mm} \mathrm{~min}^{-1}$ withdraw rate increased from $27.2^{\circ}$ to $115.5^{\circ}$.

The unmodified AR coating is hydrophilic, and therefore the adhesion force between the hydrophilic coating and silicon tip is large. With the increasing PMHS content, the surface of silica AR coating become more and more hydrophobic, and therefore the adhesion forces between the hydrophobic coating and silicon tip is smaller.

\subsection{Mechanical property}

The silica particles in base-catalyzed sol-gel silica AR coatings are kept contact only by point contact forces, and the binding forces within the coatings are therefore quite weak. ${ }^{30}$ This results in the poor mechanical property of base-catalyzed solgel silica AR coatings. ${ }^{37,38}$ As shown in Fig. 8, the Young's modulus of unmodified AR coating is $317 \mathrm{MPa}$. After being immerging in the modifier solutions with increasing PMHS solution, the Young's modulus of AR coating increases from $317 \mathrm{MPa}$ to $482 \mathrm{MPa}$, which indicates that the 0.2PMHS surface modification improves obviously the mechanical property of AR coating. This is also in good agreement with modifying process of 0.2PMHS modified AR coating as shown in Fig. 2(c). After 0.2PMHS surface modification, the individual particles of AR coating were covalently bonded together, and hence the mechanical property was improved.

\section{Conclusions}

Hydrophobic sol-gel silica AR coatings with excellent transmittance and improved mechanical property and AR stability were prepared by a PMHS (poly(methylhydrogen)siloxane) surface modification. The speculation and verification of PMHS surface modification of sol-gel silica AR coating was discussed in detail. This explains well the effect of PMHS modification on the microstructure, optical properties, hydrophobicity and mechanical property. PMHS surface modification significantly improves the hydrophobicity, mechanical property while still remaining excellent transmittance of $99.9 \%$. This PMHS surface modification will find important application in high power laser system.

\section{Acknowledgements}

The authors gratefully acknowledge the support from Natural Science Foundation of Fujian Province (2015J05092), National Natural Science Foundation of China (61505029 and 61405180).

\section{References}

1 R. E. Nowak, M. Wehse, O. Sergeev, T. Voss, M. Seyfried, K. von Maydell and C. Agert, Adv. Opt. Mater., 2014, 2, 94.

2 L. Yao and J. He, Prog. Mater. Sci., 2013, 61, 94.

3 E. I. Moses, Energy Convers. Manage., 2008, 49, 1795.
4 Y. Lee, W. Ho and C. Yeh, Appl. Surf. Sci., 2015, 354, 20.

5 L. Yan, H. Lv, C. Wang and X. Yuan, Opt. Laser Technol., 2011, 43, 232.

6 J. Q. Xi, M. F. Schubert, J. K. Kim, E. F. Schuber, M. Chen, S. Y. Lin, W. Liu and J. A. Smart, Nat. Photonics, 2007, 1, 176.

7 L. Xiao, Y. Lv, W. Dong, N. Zhang and X. Liu, ACS Appl. Mater. Interfaces, 2016, 8, 27107.

8 S. Walheim, E. Schäffer, J. Mlynek and U. Steiner, Science, 1999, 283, 520.

9 M. Ibn-Elhaj and M. Schadt, Nature, 2001, 410, 796.

10 X. Li, L. Xue and Y. Han, J. Mater. Chem., 2011, 21, 5817.

11 J. Szczyrbowski, G. Bräeuer, M. Ruske, G. Teschner and A. Zmelty, J. Non-Cryst. Solids, 1997, 218, 262.

12 J. Hiller, J. D. Mendelsohn and M. F. Rubner, Nat. Mater., 2002, 1, 59.

13 Y. Du, L. E. Luna, W. S. Tan, M. F. Rubner and R. E. Cohen, ACS Nano, 2010, 4, 4308.

14 C. Zhang, C. Zhang, J. Sun, R. Ding, Q. Zhang and X. Yao, RSC Adv., 2015, 5, 56998.

15 P. A. Sermon, M. S. W. Vong, N. Bazin, R. Badheka and D. Spriggs, Proc. SPIE, 1995, 2633, 464.

16 F. Chi, G. Wei, Q. Zhang, X. Sun, L. Zhang, X. Lu, L. Wang, F. Yi and X. Gao, App. Surf. Sci., 2015, 356, 593.

17 X. Wang and J. Shen, J. Sol-Gel Sci. Technol., 2012, 61, 206.

18 S. Kim, A. Cho, S. Kim, W. Cho, M. H. Chung, S. Kim and J. H. Kim, RSC Adv., 2016, 6, 19280.

19 X. Zhang, P. Lan, Y. Lu, J. Li, H. Xu, J. Zhang, Y. P. Lee, J. Y. Rhee, K. Choy and W. Song, ACS Appl. Mater. Interfaces, 2014, 6, 1415.

20 N. Mizoshita, M. Ishii, N. Kato and H. Tanaka, ACS Appl. Mater. Interfaces, 2015, 7, 19424.

21 I. M. Thomas, A. K. Burnham, J. R. Ertel and S. C. Frieders, Proc. SPIE, 1999, 3492, 220.

22 T. I. Suratwala, L. Hanna, E. L. Miller, P. K. Whitman, I. M. Thomas, P. R. Ehrmann, R. S. Maxwell and A. K. Burnham, J. Non-Cryst. Solids, 2003, 316, 349.

23 M. Manca, A. Cannavale, L. De marco, A. S. Aricò, R. Cingolani and G. Gigli, Langmuir, 2009, 25, 6357.

24 S. S. Latthe, H. Imai, V. Ganesan, C. Kappenstein and A. V. Rao, J. Sol-Gel Sci. Technol., 2010, 53, 208.

25 A. B. Gurav, S. S. Latthe, C. Kappenstein, S. K. Mukherjee, A. V. Rao and R. S. Vhatkar, J. Porous Mater., 2011, 18, 361.

26 S. Cai, Y. Zhang, H. Zhang, H. Yan, H. Lv and B. Jiang, ACS Appl. Mater. Interfaces, 2014, 6, 11470.

27 L. Yao, Y. Zhu, D. Qu, M. Du, J. Shen and J. Wang, SPIE, in ICO20: Optical Design and Fabrication, International Society for Optics and Photonics, 2006, p. 60340V.

28 Y. Zhang, D. Wu, Y. Sun and S. Peng, J. Sol-Gel Sci. Technol., 2005, 33, 19.

29 Y. Akamatsu, K. Makita, H. Inaba and T. Minami, Thin Solid Films, 2001, 389, 138.

30 H. G. Floch and P. F. Belleville, J. Sol-Gel Sci. Technol., 1994, 1, 293.

31 L. Zhang, Y. Xu, D. Wu, Y. Sun, X. Jiang and X. Wei, Opt. Laser Technol., 2008, 40, 282.

32 I. M. Thomas, Proc. SPIE, 1992, 1848, 281. 
33 X. Zhang, C. Cao, B. Xiao, L. Yan, Q. Zhang and B. Jiang, J. Sol-Gel Sci. Technol., 2010, 53, 79.

34 X. Zhang, B. Xia, H. Ye, Y. Zhang, B. Xiao, L. Yan, H. Lv and B. Jiang, J. Mater. Chem., 2012, 22, 13132.

35 S. S. Prakash, C. J. Brinker, A. J. Hurd and S. M. Rao, Nature, 1995, 374, 439.

36 W. T. Wang, N. Lu, J. Y. Hao, H. B. Xu, D. P. Qi and L. F. Chi, J. Phys. Chem. C, 2010, 114, 1989.

37 X. Zhang, B. Xia, B. Ding, Y. Zhang, J. Luo and B. Jiang, Mater. Lett., 2013, 104, 31033.
38 L. Xu, Z. Geng, J. He and G. Zhou, ACS Appl. Mater. Interfaces, 2014, 6, 9029.

39 L. Xu and J. He, J. Mater. Chem. C, 2013, 1, 4655.

40 F. Chi, L. Yan, H. Lv, C. Wang and X. Yuan, Thin Solid Films, 2011, 519, 2483-2487.

41 X. Zhang, W. Su, M. Lin, X. Miao, L. Ye, W. Yang and B. Jiang, J. Sol-Gel Sci. Technol., 2015, 74, 594.

42 S. Kim, J. Cho and K. Char, Langmuir, 2007, 23, 6737.

43 M. T. Nayakasinghe, A. Chakradhar, N. Sivapragasam and U. Burghaus, Appl. Surf. Sci., 2016, 364, 822.

44 S. Sarkar, S. K. Bhadra and S. Jana, RSC Adv., 2016, 6, 46048. 